\title{
Intellect and Revelation: Notes on Mullā adrā S h īrāzì's Approach in His Commentary on Usul Al-Kafi In
}

SeyedAmirHossein Asghari ${ }^{1}$ and Seyed Amirhossein Asghari ${ }^{2}$

${ }^{1}$ Affiliation not available

${ }^{2}$ Department of Middle Eastern Languages and Cultures, Indiana University

January 12, 2021

\section{Hosted file}

Intellect and Revelation- Notes on Mull \selectlanguage\{polish\}ā \selectlanguage\{english\}adr \selectlangu available at https://authorea.com/users/385880/articles/501116-intellect-and-revelationnotes-on-mul1 \%C4\%81-\%E1\%B9\%A3adr $\%$ C4 $\% 81$-s $\%$ CC $\% B 2-h \% C C \% B 2-\% C 4 \% A B r \% C 4 \% 81$ z $\%$ C4\%AB-s-approach-

in-his-commentary-on-usul-al-kafi-in 